\title{
Barreiras e fatores promotores do consumo de frutas e hortaliças entre usuários do Programa Academia da Saúde
}

\author{
Promoters and barriers to fruit \\ and vegetable consumption \\ among Health Academy \\ Program's users
}

Taís Rocha FIGUEIRA ${ }^{1}$

Aline Cristine Souza LOPES ${ }^{2}$

Celina Maria MODENA ${ }^{1}$

\section{R E S U M O}

\section{Objetivo}

Investigar barreiras e fatores promotores do consumo de frutas e hortaliças entre usuários do Programa Academia da Saúde.

\section{Métodos}

Estudo qualitativo conduzido em seis polos do Programa Academia da Saúde em Belo Horizonte, Minas Gerais. Foram realizadas entrevistas semiestruturadas com 62 usuários. A análise de conteúdo foi desenvolvida com auxílio do software NVivo10.

\section{Resultados}

As principais barreiras identificadas foram: comércio inadequado, baixo poder aquisitivo, preço, carência de iniciativas públicas, falta de tempo, preguiça, fruta ser considerada apenas uma alternativa alimentar e não realizar o jantar. Os fatores promotores mais citados foram: saúde, prevenção/controle de doenças, gostar, hortaliça ser considerada como parte da refeição, criação e origem familiar, melhoria da situação financeira, comércio próximo e estratégias de compra.

\footnotetext{
1 Fundação Oswaldo Cruz, Centro de Pesquisas René Rachou, Laboratório de Educação em Ambiente e Saúde. Av. Augusto de Lima, 1715, Barro Preto, 30190-002, Belo Horizonte, MG, Brasil. Correspondência para/Correspondence to: ACS LOPES. E-mail: <alinelopesenf@gmail.com><aline@enf.ufmg.br>.

2 Universidade Federal de Minas Gerais, Escola de Enfermagem, Departamento de Nutrição. Belo Horizonte, MG, Brasil.
} 


\section{Conclusão}

É necessário ampliar o acesso às frutas e às hortaliças por meio do fortalecimento das iniciativas públicas para aumento da produção e diminuição dos preços desses alimentos e ampliação do comércio local. As intervenções educativas devem focar a construção de outros sentidos para o consumo que não se restrinjam ao discurso saúde-doença e soluções viáveis que facilitem o consumo de frutas e hortaliças no cotidiano, seja pela proposição de estratégias de aquisição de frutas e hortaliças ou pela ampliação de habilidades culinárias para preparações mais práticas.

Palavras-chave: Consumo de alimentos. Frutas. Verduras.

\section{A B S T R A C T}

\section{Objective}

To investigate promoters and barriers to fruit and vegetable consumption among Health Academy Program's users.

\section{Methods}

This qualitative study was conducted in six Health Academy Program's units in Belo Horizonte, Minas Gerais. Semi-structured interviews were conducted with 62 users. Content analysis was performed using the software NVivo10.

\section{Results}

The main barriers to fruit and vegetable consumption were: limited access, low purchasing power, price, lack of public initiatives, lack of time, laziness, fruit being considered no more than a food alternative, and not having supper. The most common promotion factors were: health, disease prevention/control, taste, vegetable being considered part of a meal, family habit and background, raise in income, nearly outlets, and purchasing strategies.

\section{Conclusion}

It is necessary to expand access to fruits and vegetables by strengthening public initiatives that reduce prices and increase production and the number of outlets. Educational interventions should focus on creating reasons for consuming not limited to the health-disease discourse and viable solutions that facilitate the daily intake of fruits and vegetables, either by developing strategies for the acquisition of fruits and vegetables or by expanding the cooking skills to include more practical preparations.

Keywords: Food consumption. Fruit. Vegetables.

\section{N T R O D U Ç Ã O}

As frutas e as hortaliças são importantes componentes de uma alimentação saudável, pois são fornecedoras da maior parte dos micronutrientes, fibras e componentes funcionais essenciais. Ademais, seu consumo pode ajudar a substituir alimentos com altas concentrações de gorduras saturadas, açúcar e sal, o que favorece a saúde'.

A promoção do consumo de frutas e hortaliças é indicada pela Organização Mundial de Saúde como prioridade nas políticas nutricionais, alimentares e agrícolas pelo potencial em diminuir o risco de Doenças Crônicas Não Transmissíveis
(DCNT)2. O consumo insuficiente de frutas e hortaliças é apontado como um dos dez principais fatores de risco para a ocorrência de DCNT, sendo atribuído como responsável por 19\% dos casos de câncer gastrointestinal, 31\% das doenças cardíacas isquêmicas e $11 \%$ dos acidentes vasculares cerebrais ${ }^{3}$. Estima-se que a ingestão de quantidades adequadas de frutas e hortaliças, ou seja, $400 \mathrm{~g}$ diárias, poderia evitar 1,7 milhões de mortes e 16 milhões de incapacidades anualmente no mundo 4 .

Apesar das evidências e orientações para o incentivo do consumo desses alimentos, a quantidade recomendada de ingestão não é atingida 
em vários países ${ }^{2}$. No Brasil, dados da Pesquisa de Orçamentos Familiares ${ }^{5}$ revelaram que menos de $10,0 \%$ da população consumiam diariamente a quantidade recomendada. Os resultados do sistema Vigilância de Fatores de Risco e Proteção para Doenças Crônicas por Inquérito Telefônico $\left(\right.$ Vigitel) ${ }^{6}$ revelaram que apenas $23,6 \%$ dos brasileiros consumiam cinco ou mais porções de frutas e hortaliças por dia, em cinco ou mais dias da semana.

Essa inadequação no consumo de frutas e hortaliças perpassa por questões individuais, socioculturais, econômicas, agrícolas e ambientais ${ }^{2}$, sendo preço, tempo e sabor identificados como as principais barreiras ${ }^{7-16}$. Entretanto, alguns fatores têm-se mostrado capazes de estimular a ingestão desses alimentos, entre eles sua ação promotora da saúde, manutenção do peso saudável, preferência alimentar e apoio famíliar9,12-17.

Ações de incentivo ao consumo de frutas e hortaliças foram apontadas como uma das prioridades do "Plano Nacional de Ações Estratégicas para o Enfrentamento das Doenças Crônicas Não Transmissíveis no Brasil" "18. Em Belo Horizonte (MG), a promoção do consumo de frutas e hortaliças está prevista dentro da Política Municipal de Segurança Alimentar e Nutricional, destacando-se a comercialização de produtos hortifrutigranjeiros de qualidade e a preços mais acessíveis do que o comércio regular por meio de estabelecimentos do tipo sacolão e feiras livres ${ }^{19}$.

Desvelar novos processos e fenômenos sobre os condicionantes do consumo de frutas e hortaliças é fundamental para a construção de ações e fortalecimento das iniciativas públicas existentes, de forma a auxiliar na elaboração de soluções efetivas e sustentáveis para o aumento do consumo. Dessa forma, este estudo qualitativo objetivou investigar barreiras e fatores promotores do consumo de frutas e hortaliças entre usuários do Programa Academia da Saúde de modo a gerar evidências científicas que permitissem contribuir para seu aprimoramento no que se refere às ações de incentivo ao consumo desse grupo alimentar.

\section{M É T O D O S}

Realizou-se estudo qualitativo do tipo exploratório e descritivo em seis polos do Programa Academia da Saúde em Belo Horizonte, Minas Gerais. O Programa Academia da Saúde é um ponto da Atenção Primária à Saúde do Sistema Único de Saúde e visa referenciar-se como um programa de promoção da saúde, prevenção e atenção às DCNT, ofertando atividades físicas e corporais, ações de promoção da alimentação saudável e demais modos saudáveis de vida ${ }^{20}$. Em Belo Horizonte, esse serviço, anteriormente denominado Academia da Cidade, foi implantado em 2006 em áreas com média a elevada vulnerabilidade social, existindo, atualmente, 53 polos.

A pesquisa, objeto do presente artigo, constitui parte de um Projeto maior denominado "Consumo de frutas e hortaliças em polos do Programa Academia da Saúde de Belo Horizonte, Minas Gerais: fatores associados e intervenções nutricionais". O projeto envolve três fases: identificação dos fatores individuais, familiares e ambientais associados ao consumo de frutas e hortaliças; comparação dos resultados para verificar a influência da vulnerabilidade à saúde, da segurança alimentar e nutricional e de equipamentos sociais sobre o consumo de frutas e hortaliças e, por fim, delineamento, implementação e avaliação de intervenções educativas. Este estudo faz parte da primeira fase do projeto.

O projeto maior foi desenvolvido em 18 polos sorteados aleatoriamente e alocados em grupos intervenção e controle. Esta pesquisa qualitativa não pretendia englobar todos os polos do Projeto, sendo utilizado o critério de saturação ${ }^{21}$ para estabelecer a interrupção do trabalho de campo. Dessa forma, optou-se por estudar os polos do grupo intervenção devido à importância em se conhecer previamente as noções que os sujeitos têm de determinado fenômeno para o desenvolvimento dos processos educativos e, portanto, para a elaboração das intervenções que seriam conduzidas na terceira fase do projeto. É importante salientar que os polos não conheciam 
sua condição de grupo intervenção e que a coleta dos dados qualitativos só se iniciava após a finalização da coleta dos dados quantitativos para evitar possíveis vieses. Os polos participantes deste estudo foram definidos segundo a ordem de ingresso em campo estabelecida para a coleta de dados do projeto maior, atingindo-se o total de seis polos.

Os participantes desta pesquisa foram selecionados a partir da amostra do estudo quantitativo de linha de base do Projeto maior. Foram adotados como critérios de inclusão: ser maior de 20 anos, responsável pela aquisição e/ou preparo dos gêneros alimentícios no domicílio, frequentar as atividades do Programa Academia da Saúde e ser alocado no grupo intervenção do projeto maior. A relação de participantes elegíveis foi estratificada numa combinação de seis categorias demográficas de acordo com sexo (feminino e masculino) e faixa etária (20 a 39 anos, 40 a 59 anos e 60 ou mais anos), com objetivo de garantir maior heterogeneidade, visto que essas características podem influenciar o consumo alimentar. Posteriormente, foram sorteados aleatoriamente dois usuários por categoria demográfica em cada um dos polos estudados, definição

Tabela 1. Características socioeconômicas dos 62 participantes. Belo Horizonte (MG), 2013.

\begin{tabular}{lcc}
\hline Características & $\mathrm{n}$ & $\%$ \\
\hline Sexo & & \\
Feminino & 36 & 58,1 \\
Masculino & 26 & 41,9 \\
Faixa etária & & \\
20 a 39 anos & 14 & 22,6 \\
40 a 59 anos & 24 & 38,7 \\
$\geq 60$ anos & 24 & 38,7 \\
Escolaridade & & \\
Sem estudo & 3 & 4,8 \\
até 4 anos & 23 & 37,1 \\
5 a 8 anos & 7 & 11,3 \\
9 a 11 anos & 21 & 33,9 \\
$\geq 12$ anos & 8 & 12,9 \\
Renda familiar (salários mínimos) & & \\
até 4 & 49 & 79,0 \\
5 a 9 & 9 & 14,5 \\
$\geq 10$ & 4 & 6,5 \\
\hline
\end{tabular}

baseada em estudo multicêntrico desenvolvido por Maman et al.22. O convite para participar da pesquisa foi realizado por meio de contato telefônico; em caso de recusa, sorteava-se um novo entrevistado. Ao final da coleta de dados, foram entrevistados 62 usuários, pois, na categoria sexo masculino e faixa etária entre 20 e 39 anos, havia quatro usuários elegíveis, e, destes, dois aceitaram participar da pesquisa. As características da amostra podem ser visualizadas na Tabela 1 .

As entrevistas foram realizadas pela pesquisadora principal durante o período de abril a novembro de 2013 no espaço do Programa Academia da Saúde. O roteiro englobou questões relativas às práticas alimentares, consumo e aquisição de frutas e hortaliças. As entrevistas foram gravadas, transcritas na íntegra e tiveram uma duração média de 30 minutos.

A análise de conteúdo ${ }^{23}$ das entrevistas foi executada com auxílio do software NVivo 10 (Targetware Infomatica Ltda, São Paulo). Realizou-se a leitura flutuante das transcrições de forma a identificar as unidades de registro, as quais foram codificadas em categorias de modo a agrupar aquelas que, em algum sentido, compartilhavam a mesma ideia teórica e descritiva ${ }^{24}$. Em seguida, as categorias foram analisadas e distribuídas entre duas categorias maiores: barreiras ao consumo de frutas e hortaliças e fatores promotores do consumo de frutas e hortaliças.

Os entrevistados foram identificados por meio de código formado pelas letras $A$ e E seguidas cada uma por numeração arábica. A letra A se refere ao polo do Programa Academia da Cidade, e varia de $A 1$ a A6, e a letra E corresponde ao entrevistado, variando de acordo com o número de participantes em cada polo.

Este estudo foi aprovado pelo Comitê de Ética em Pesquisa da Universidade Federal de Minas Gerais ( $n^{\circ}$ 0537.0.0203.000-11) e da Secretaria Municipal de Saúde de Belo Horizonte ( $n^{\circ}$ 0537.0.0203.410-11A). Os participantes receberam explicações sobre os objetivos da pesquisa e a confidencialidade dos dados coletados e assinaram o Termo de Consentimento Livre e Esclarecido antes da realização da entrevista. 


\section{RES U L T A D O S}

O Quadro 1 resume as barreiras e os fatores promotores do consumo de frutas e hortaliças identificados neste estudo.

\section{Barreiras ao consumo de frutas e hortaliças}

Uma das principais barreiras ao consumo de frutas e hortaliças apontada pelos entrevistados relacionava-se ao comércio local, visto como inadequado:

Aqui no bairro além de ser caro, as coisas não são boas (A6E10); O sacolão perto da minha casa não oferece qualidade e nem variedade, por isso muitas vezes a gente não come determinada fruta (A1E1); A distância de buscar, tem dia que a gente come arroz, feijão e carne, só, porque não vai lá buscar verdura (A2E9).

Essas características negativas comprometiam a disponibilidade domiciliar de frutas e hortaliças, e a busca por melhores opções fora do bairro nem sempre era uma alternativa viável devido às dificuldades de transporte: "Sempre reclamo com o menino: vou comprar lá em cima, que é mais barato. Mas aí tem a locomoção. Se você vai de ônibus, tem que voltar de táxi, como é que você volta de ônibus com um tanto de sacola?" (A2E8).

A falta de qualidade dos comércios locais era vista por alguns como resultante do baixo poder aquisitivo da população. Na construção desse raciocínio, a qualidade acabava sendo categorizada segundo a classe social. Dessa forma, algo que a princípio seria considerado de baixa qualidade passava a ser adequado:

Se eles melhorassem, assim, mais qualidade, também, é na entrada da favela o sacolão. Então eles não trazem muita coisa de primeira porque se tiver cara o povo não compra. O povo vai mais pelo preço, então pra gente que é pobre tá bom o sacolão que tem aí (A2E3).

Além de favorecer a obtenção de produtos de menor qualidade, o baixo poder aquisitivo restringia a variedade e a quantidade dos alimentos adquiridos: "Desde a hora que você tem um dinheirinho, que você não pode comprar um quilo, você compra meio. Diminui, mas você compra" (A2E2). Esse contexto piorava no final do mês ou na presença de imprevistos financeiros, quando era necessário reduzir gastos. Havia

Quadro 1. Barreiras e fatores promotores do consumo de frutas e hortaliças.

\begin{tabular}{ll}
\hline Barreiras & Promotores \\
\hline Comércio inadequado & Saúde \\
Dificuldade de transporte & Prevenção/controle de doenças \\
Baixo poder aquisitivo & Aquisição de conhecimento \\
Preço & Vivenciar consequências de doenças crônicas não transmissíveis \\
Carência de políticas públicas & Desejo de emagrecer \\
Falta de tempo & Substituir alimentos prejudiciais \\
Preguiça & Hortaliças como inerentes à refeição \\
Fruta como apenas uma alternativa & Criação familiar \\
Falta de hábito & Origem interiorana/rural \\
Esquecimento & Comercialização \\
Falta de vontade & Melhoria do poder aquisitivo \\
Não jantar & Gostar \\
Presença de agrotóxicos & Preço baixo \\
Restrições alimentares & Boa qualidade \\
Baixa digestibilidade & Estabelecer estratégias de compra \\
Não gostar & Proximidade do comércio \\
Edentulismo & Cultivar \\
\hline
\end{tabular}


pouco dinheiro para muitas despesas e como as frutas e as hortaliças são produtos perecíveis, tornava-se difícil a realização de um estoque no momento em que se recebia o salário, sendo comum a redução do consumo no decorrer do mês: "Fruta, leite, verdura mais no finalzinho costuma faltar, aí faz um macarrão, arroz, feijão" (A6E1).

As frutas eram consideradas menos acessíveis que as hortaliças devido ao preço, embora ambas fossem percebidas como alimentos caros. Aquelas com menor custo eram selecionadas para compor o cardápio familiar, estabelecendo-se uma dieta monótona: "Não tem como ficar fazendo tantas variedades justamente por causa do preço. Há vontade da gente colocar outros tipos de frutas, só que o preço infelizmente não dá" (A3E6).

Alguns entrevistados apontaram uma carência de iniciativas públicas destinadas a facilitar o acesso da população às frutas e hortaliças. As colocações se referiam tanto à falta de subsídios fiscais para redução dos preços quanto à ausência de um sistema de controle de qualidade dos alimentos. Ademais, sentiam que o governo colocava o indivíduo como o responsável pela adoção de uma alimentação saudável, eximindo-se de suas responsabilidades para o desenvolvimento de ambientes favoráveis a essa escolha:

Os governantes não tão preocupados com qualidade de uma verdura tão preocupados só em arrecadar o imposto que lhe é dado ... Eles ficam jogando pra cima da população, às vezes até uma população pobre, carente, pra poder solucionar problemas relativos à alimentação (A3E7).

O processo de compra de frutas e hortaliças era ainda influenciado por fatores como falta de tempo e preguiça: "Às vezes não tem tempo nem de comprar", "às vezes a gente na correria danada" (A5E8); "Quando acaba eu sempre levo uns dois dias pra comprar, de preguiça de caçar supermercado" (A1E6). Essas barreiras também interferiam no preparo dos alimentos e na realização das refeições: "Onde eu trabalho é um pique direto, às vezes não dá tempo de ir na cozinha pegar uma fruta" (A3E1); "Trabalhoso. Principalmente salada, às vezes não faço por preguiça" (A6E10). A preguiça era deflagrada quando se considerava a tarefa desagradável ou trabalhosa, quando o usuário se sentia desanimado ou apresentava característica de procrastinador.

Barreiras relacionadas ao momento da escolha alimentar também apareceram nos relatos dos entrevistados. A fruta, muitas vezes, era compreendida como uma alternativa de lanche: "Às 3:00 horas eu como uma fruta ou um iogurte" (A5E3). Essa concepção aliada a fatores como falta de hábito, de vontade e esquecimento levavam a uma diminuição da frequência de consumo. É possível perceber a necessidade de uma racionalização para o consumo da fruta acontecer: "Tem hora que eu vou na barrinha de cereal e penso porque não vou na fruta, às vezes eu largo e vou na banana" (A1E1).

A ingestão de hortaliças era associada às refeições principais e, dessa forma, a descontinuidade do hábito de jantar, característico na população pesquisada, contribuiu para que seu consumo fosse reduzido: "Tomo um leite, como um pedaço de pão, mas jantar mesmo, raramente eu janto. Até porque se eu janto, eu tenho pesadelo" (A5E10). Outras justificativas para trocar o jantar pelo lanche envolveram a falta de vontade de comer comida, a percepção de que jantar engorda e o desejo por maior praticidade no preparo da refeição.

\section{Fatores promotores do consumo de frutas e hortaliças}

O principal fator motivador para o consumo de frutas e hortaliças estava relacionado à percepção de seus benefícios para a saúde ou para prevenção/controle de determinada doença. Os efeitos produzidos pelas frutas e hortaliças foram exaltados pelos entrevistados:

Eu sinto melhor, mais disposta (A1E10); $\dot{E}$ bom para o funcionamento do intestino, 
para o controle de pressão, controle de diabetes (A1E3); "Emagrece" (A1E5); Não vai ocorrer problema de anemia (A2E1); Tira a ansiedade (A2E1); É bom pra pele, pro cabelo (A3E6); É bom pra memória (A4E9); Pra não ter gripe e tudo, mas eu sei que é rico em vitaminas e fibras (A5E9).

A aquisição de conhecimento proporcionada pelo profissional de saúde, mídia ou no próprio Programa Academia da Cidade sobre os benefícios produzidos pelas frutas e hortaliças estimulou o consumo desses alimentos, especialmente quando os usuários possuíam alguma disfunção orgânica, vivenciavam as consequências das DCNT ou desejavam emagrecer: "A gente não tinha essa informação ... achava que não fazia tanta falta ... nessa deficiência de vitaminas, se tivesse ingerindo as frutas não teria dado o problema ... agora eu to comendo até mais de quatro frutas ..." (A6E6)

A concepção medicalizadora das frutas e hortaliças favoreceu o entendimento de que estes são alimentos substitutos. As frutas foram relatadas como substitutos das guloseimas durante os lanches, pois "Ao invés de ficar comendo besteiras, come a fruta" (A2E4), e as verduras para reduzir quantidades ingeridas de alimentos ricos em carboidratos complexos e gordura nas refeições principais: "Como eu não posso comer muito arroz, então eu como mais o legume, a verdura" (A2E3). Apesar da concepção de substituto, diferentemente das frutas, as hortaliças não são percebidas apenas como uma alternativa saudável, mas como alimentos inerentes às refeições principais: "Agora legume eu como todo dia, faz parte do meu prato" (A1E7); "Eu não sei comer arroz e carne, a verdura pra mim ela tem que tá no meu prato, eu fui criada assim" (A4E8). É algo que antecede ao discurso medicalizador, assim, os conhecimentos adquiridos atualmente vêm mais reforçar a ingestão ou aumentar a quantidade consumida.

Para vários entrevistados, a criação familiar e o fato de terem origem rural ou interiorana foram importantes influências para a formação do hábito de consumir frutas e hortaliças: "Que a gente foi criada com muita folha de taioba, almeirão" (A4E10); "Mamão eu gosto desde pequeninha, desde lá da roça, pegava no quintal, comia e até hoje eu como" (A6E10).

Embora presentes durante o ciclo de vida, os usuários relataram que, atualmente, o consumo de frutas e hortaliças melhorou devido à facilidade de encontrá-las em estabelecimentos comerciais e pela melhoria do poder aquisitivo: "Hoje a gente tem uma fartura maior e facilidade pra poder comprar. Antes eles tinham uma dificuldade financeira grande, hoje a gente não" (A2E4); "Come mais porque aqui não falta, sempre nos armazéns a gente encontra. Na roça tem a época pra tudo" (A2E3).

Além de beneficiar a saúde, as frutas e hortaliças eram vistas como alimentos que, de uma maneira geral, agradavam o paladar: "Come porque gosta e geralmente compra só mesmo a que a família gosta" (A2E4). Não se gosta de todos os tipos, mas sempre se gosta de certa variedade que também agrada os membros da família, fazendo com que sejam selecionados para compor a dieta, principalmente quando estão com bom preço e qualidade.

O preço baixo foi relatado como uma forma de garantir a compra de uma maior quantidade destes alimentos: "Ás vezes tem umas ofertas e a gente aproveita mais" (A4E3), assim como a qualidade por favorecer uma maior durabilidade dos produtos: "O chuchu tá novinho, em vez de comprar um, eu já compro dois porque aí aguenta mais um pouquinho" (A1E1). A qualidade do alimento ainda despertava o desejo, pois a beleza e o cheiro do produto eram capazes de cativar o apetite: "Vê aquelas verdura bonita, a gente vai lá, compra, aí a gente chega em casa com aquela vontade de comer" (A4E4).

Uma forma encontrada por alguns entrevistados para adquirir maiores quantidades de frutas e hortaliças com maior conveniência, melhor preço e qualidade foi estabelecer estratégias de compra, como: 
Procuro ir no dia que chegou (A1E2); Faço pesquisa, vejo onde tá o preço mais em conta (A4E1); Fruta da época que é sempre mais barato (A5E9); Compro aquela quantidade pra semana (A1E1); Comprar um já pra você comer na semana e o outro mais verdinho, que ele vai madurecendo (A3E1); Açougue, é farmácia, sacolão eu já vou e faço tudo de uma vez (A2E8).

Além das estratégias adotadas, os entrevistados relataram que o comércio próximo de casa, do trabalho ou do Programa Academia da Cidade era um grande facilitador para a aquisição de frutas e hortaliças: "Vou lá e busco mais, que o sacolão é pertinho de casa" (A2E1).

Alguns entrevistados apontaram ainda a praticidade decorrente de uma horta no quintal, pois não precisa sair de casa, não tem que pagar e não há uso de agrotóxico: "A gente tá com uma hortinha lá em casa pra poder ajudar. Porque essa alimentação que a gente busca aí fora não é tão saudável assim" (A6E5).

\section{I S C U S S Ã O}

As principais barreiras ao consumo de frutas e hortaliças identificadas estavam relacionadas ao acesso a estes alimentos, dificultado por fatores como comércio local inadequado, alto custo, baixo poder aquisitivo e carência de políticas públicas. Estas barreiras se inter-relacionavam e produziam um efeito cumulativo negativo sobre a disponibilidade domiciliar, a quantidade e variedade de frutas e hortaliças consumidas.

Dentre as barreiras citadas, o alto custo é o mais recorrente na literatura ${ }^{7-11,13-15}$, em contrapartida ao poder aquisitivo, encontrado apenas em Eikenberry \& Smith ${ }^{9}$ e Lucan et al. ${ }^{15}$. Cassady et al. ${ }^{25}$ chamam atenção para o fato do preço nem sempre ser o maior empecilho para o consumo de frutas e hortaliças entre a população de baixa renda. Segundo os autores, o consumo adequado dependeria de um rearranjo do orçamento familiar e que esse ajuste pode ser uma barreira maior que o preço. No presente trabalho, verificou-se que o movimento de rearranjo orçamentário é realizado por muitos entrevistados e ocorre de forma a reduzir as frutas e hortaliças do cardápio, pois há priorização de outras despesas. Em conformidade com os resultados aqui encontrados sobre estimuladores do consumo, Claro \& Monteiro ${ }^{26}$ observaram que o aumento da renda e a diminuição dos preços de frutas e hortaliças são capazes de aumentar sua participação na dieta dos brasileiros, colocando estas ações no centro do desenvolvimento de políticas públicas.

No que se refere ao comércio local, este foi identificado como inadequado devido ao alto custo dos alimentos, baixa qualidade e localização inconveniente, o que está de acordo com a literatura7, 10,13,15. John \& Ziebland ${ }^{10}$ verificaram que o alto custo e inacessibilidade ao comércio são os fatores mais difíceis de serem alterados por intervenções educativas, sendo necessária a implementação de políticas públicas para auxiliar no seu enfrentamento.

No Brasil, existem iniciativas públicas que sugerem o aumento da produção de frutas e hortaliças e a diminuição de seus preços por meio de medidas fiscais, mas não preveem a criação de dispositivos jurídicos que permitam a implementação das propostas ${ }^{18,27}$. Em Belo Horizonte $(\mathrm{MG})$, destaca-se dentro da política de segurança alimentar o programa ABasteCer, que consiste em 21 estabelecimentos comerciais fiscalizados pelo governo de modo a garantir à população produtos hortifrutigranjeiros de qualidade e a preços tabelados, em média 30\% mais baratos do que o comércio regular ${ }^{19}$. O pequeno número destes estabelecimentos e sua localização distante das áreas de moradia dos entrevistados pode ter contribuído para que os entrevistados não sentissem o impacto desse programa sobre seu cotidiano, o que demonstra a necessidade de expansão e mobilização comunitária para seu fortalecimento. Uma medida a ser analisada seria a convergência geográfica entre programa ABasteCer e Programa Academia da Cidade, pois como se 
observou, a proximidade com o comércio aumenta a oportunidade de compra de frutas e hortaliças, tornando-a mais conveniente. Além disso, a instalação desse tipo de estabelecimento permitiria uma melhoria do comércio local, algo considerado improvável pelos usuários devido a sua condição econômica.

Outra ação promissora seria o incentivo às hortas comunitárias visto que alguns entrevistados possuem hortas particulares, podendo atuar como agentes multiplicadores da técnica do cultivo e pelo fato desta população ter raízes rurais. O resgate da cultura rural por uma intervenção educativa poderia não só encorajar práticas de cultivo, como também o reencontro com sabores e lembranças capazes de ampliar o consumo de frutas e hortaliças para além de modelos racionais baseados no processo saúde-doença. De acordo com Walsh \& Kiviniemi ${ }^{28}$, os sentimentos e emoções relacionados a um alimento exercem uma estreita influência sobre as escolhas realizadas e o fomento à construção de associações afetivas positivas são capazes de estimular o consumo de frutas e hortaliças.

Diante das dificuldades de acesso vivenciadas, os entrevistados procuram amenizar a situação estabelecendo estratégias para a aquisição das frutas e hortaliças, as quais deveriam ser discutidas e aprimoradas em intervenções educativas para o estabelecimento de planos de ação que facilitem o consumo de frutas e hortaliças. $\mathrm{O}$ planejamento das compras torna-se também importante pelo tempo ser um recurso limitado atualmente, e sua maior ou menor disponibilidade fazer com que se administrem e determinem as práticas alimentares ${ }^{29}$.

A falta de tempo apareceu como um obstáculo para a compra, preparo e consumo de frutas e hortaliças, assim como o estado de preguiça. Na literatura, vários estudos discutiram a escassez de tempo como barreira ao consumo de frutas e hortaliças ${ }^{7-16}$, o que não ocorreu em relação à preguiça ${ }^{10,16}$. Além de poucos, os estudos que observaram a preguiça como um obstáculo não promoveram uma análise sobre o tema que permitisse entender melhor em que circunstâncias ocorria. A compreensão sobre como a preguiça se manifesta, em que ocasiões e quais fatores a induzem são importantes para o desenvolvimento de práticas educativas que superem o caráter pejorativo e culpabilizador que este sentimento carrega nas diferentes culturas. No presente trabalho, a preguiça apareceu quando a tarefa era considerada desagradável ou trabalhosa, quando o usuário sentia desânimo ou apresentava característica de procrastinador. Seria interessante problematizar estas questões em intervenções educativas, pois até onde o sentimento de preguiça vem sendo usado de forma a encobrir o cansaço proveniente das demandas do mundo moderno, a disputa de tempo entre estas inúmeras atividades ou simplesmente a escolha por opções de vida mais práticas que permitam maior dedicação às atividades consideradas prazerosas.

Soluções estão sendo capitalizadas pela indústria e comércio, apresentando alternativas de produtos alimentícios que se adaptam às condições urbanas, permitindo que se ganhe tempo, diminua o trabalho e possam ser facilmente transportados ${ }^{30}$. Dentro desse contexto, o desenvolvimento de tecnologias que tornem a higienização, armazenamento, conservação, preparo e transporte de frutas e hortaliças mais práticos, a um custo razoável, torna-se fundamental. O estímulo à produção de alimentos minimamente processados, com subsídios fiscais para redução do preço, seria um investimento promissor.

Assim como observado em inúmeros estudos ${ }^{9,12-17}$, a saúde foi apontada como um dos principais motivadores para o consumo de frutas e hortaliças. Contudo, nem sempre este argumento foi suficiente para criar o hábito de se ingerir frutas, já que são reconhecidas outras opções de lanche considerados saudáveis, como barra de cereal e iogurte, e o desejo de exercer um efeito importante sobre a escolha alimentar.

Com relação às hortaliças, as informações sobre efeitos benéficos à saúde possuem mais um efeito reforçador de consumo, visto que esses ali- 
mentos já são considerados como parte essencial das refeições principais. Neste caso, o fator que desfavorece a ingestão é o abandono da prática do jantar, o que coloca a necessidade de resgatar este hábito ao se divulgar o preparo de pratos leves e práticos que incluam hortaliças e ao promover a desconstrução do jantar como causa de obesidade. O Guia Alimentar para a População Brasileira pode ser usado como auxiliar neste processo, visto que recomenda a realização do jantar e apresenta opções saudáveis para sua composição ${ }^{31}$.

\section{CONCLUSÃ O}

O acesso às frutas e hortaliças pela população pesquisada é limitado pelo comércio local inadequado, alto custo e baixo poder aquisitivo. As iniciativas públicas existentes não têm sido suficientes para reverter esta situação, havendo necessidade da criação de dispositivos que permitam o aumento da produção e diminuição dos preços destes alimentos, bem como uma localização geográfica dos equipamentos públicos que permitam maior conveniência para a compra e o estímulo a hortas comunitárias.

A falta de tempo e a preguiça apareceram como obstáculos para a compra, preparo e consumo de frutas e hortaliças. Estes fatores devem ser problematizados em intervenções educativas para o encontro de soluções viáveis que permitam maior facilidade para o consumo de frutas e hortaliças no cotidiano, seja pelo desenvolvimento de estratégias para aquisição de frutas e hortaliças ou pela ampliação de habilidades culinárias para preparações práticas e baratas. É importante ainda que se invista em tecnologias que tornem a higienização, armazenamento, conservação, preparo e transporte de frutas e hortaliças mais práticos.

Um dos principais motivadores para o consumo de frutas e hortaliças foi a saúde. Contudo, nem sempre este argumento foi suficiente para criar o hábito de se ingerir frutas, o que aponta a necessidade de estimular a construção de outros sentidos para o consumo que não se restrinjam ao discurso saúde-doença. Para a população investigada esse processo poderia ser iniciado pelo resgate da cultura rural/interiorana, o que poderia encorajar práticas de cultivo e permitir o reencontro com sabores e lembranças capazes de ampliar o consumo de frutas e hortaliças para além de modelos racionais.

\section{COLABORADORES}

TR FIGUEIRA participou da elaboração e desenho do projeto, análises e interpretações dos dados e redação do artigo. ACS LOPES e CM MODENA participaram da elaboração e desenho do projeto e revisão crítica do artigo.

\section{REFERÊ N C I A S}

1. Jaime PC, Figueiredo ICR, Moural EC, Malta DC. Fatores associados ao consumo de frutas e hortaliças no Brasil, 2006. Rev Saúde Pública. 2009; 43(Supl. 2):57-64. http://dx.doi.org/10.1590/S00 34-89102009000900008

2. World Health Organization. Fruit and vegetables for health. Report of a Joint FAOMHO Workshop 1-3 September 2004. Kobe: WHO; 2004.

3. World Health Organization. The World Health Report 2002: Reducing risks, promoting healthy life. Geneva: WHO; 2002

4. World Health Organization. Global status report on noncommunicable diseases 2010. Geneva: WHO; 2011.

5. Instituto Brasileiro de Geografia e Estatistica. Pesquisa de orçamentos familiares 2008-2009: avaliação nutricional da disponibilidade domiciliar de alimentos no Brasil. Rio de Janeiro: IBGE; 2010.

6. Brasil. Ministério da Saúde. Vigitel Brasil 2013: Vigilância de Fatores de Risco e Proteção para Doenças Crônicas por Inquérito Telefônico. Brasília: Ministério da Saúde; 2014.

7. Anderson A, Cox D. Five a day: Challenges and achievements. Nutr Food Sci. 2000; 3(1):30-4. http:// dx.doi.org/10.1108/00346650010304747

8. Biloukha OO, Utermohlen V. Healthy eating in Ukraine: Attitudes, barriers and information sources. Public Health Nutr. 2001; 4(2):207-15. http://dx.doi. org/10.1079/PHN200059

9. Eikenberry N, Smith C. Healthful eating: Perceptions, motivations, barriers, and promoters in low-income 
Minnesota communities. J Am Diet Assoc. 2004; 104(7):1158-61. http://dx.doi.org/10.1016/j.jada. 2004.04.023

10. John J, Ziebland S. Reported barriers to eating more fruit and vegetables before and after participation in a randomized controlled trial: A qualitative study. Health Educ Res. 2004; 19(2):165-74. http://dx.doi. org/10.1093/her/cyg016

11. Goug B, Conner MT. Barriers to healthy eating amongst men: A qualitative analysis. Social Sci Med. 2006; 62(2):387-95. http://dx.doi.org/10.1016/j. socscimed.2005.05.032

12. McGee BB, Richardson V, Johnson GS, Thornton A, Johnson C, Yadrick K, et al. Perceptions of factors influencing healthful food consumption behavior in the lower Mississippi Delta: Focus group findings. J Nutr Educ Behav. 2008; 40(2):102-9. http://dx.doi. org/10.1016/J.JNEB.2006.12.013

13. Yeh MC, Ickes SB, Lowestein LM, Shuval K, Ammerman AS, Farris $R$, et al. Understanding barriers and facilitators of fruit and vegetable consumption among a diverse multi-ethnic population in the USA. Health Prom Int. 2008; 23(1):42-51. http://dx.doi.org/10.1093/heapro/ dam044

14. Olivares SC, Lera LM, Mardones MAH, Araneda JF, Olivares MAC, Colque MEM. Motivaciones y barreras para consumir 5 porciones de frutas y verduras al día en madres de escolares y professores de enseñanza básica. Archivos Latinoam Nutr. 2009; 59(2):166-73.

15. Lucan SC, Barg FK, Long JA. Promoters and barriers to fruit, vegetable, and fast-food consumption among urban, low-income African Americans: A qualitative approach. Am J Public Health. 2010; 100(4):631-5.

16. Silva CL, Costa THM. Barreiras e facilitadores do consumo de frutas e hortaliças em adultos de Brasília. Sci Med. 2013; 23(2):68-74.

17. Pollard J, Greenwood D, Kirk S, Cade J. Motivations for fruit and vegetable consumption in the UK Women's Cohort Study. Public Health Nutr. 2002; 5(3):479-86. http://dx.doi.org/10.1079/PHN20013 11

18. Brasil. Ministério da Saúde. Plano de ações estratégicas para o enfrentamento das Doenças Crônicas Não Transmissíveis (DCNT) no Brasil. Brasília: Ministério da Saúde; 2011.

19. Prefeitura de Belo Horizonte. Secretaria Adjunta de Segurança Alimentar e Nutricional. Programa ABasteCer. Belo Horizonte: Prefeitura de Belo Horizonte; 2014 [acesso 2014 set 10]. Disponível em: http://portalpbh.pbh.gov.br
20. Brasil. Ministério da Saúde. Portaria $n^{\circ} 2681$, de 7 de novembro de 2013. Redefine o Programa Academia da Saúde no âmbito do Sistema Único de Saúde. Diário Oficial da União. 2013; 7 nov.

21. Minayo MCS. O desafio do conhecimento: pesquisa qualitativa em saúde. São Paulo: Hucitec; 2008.

22. Maman S, Abler L, Parker L, Lane T, Chirowodza A, Ntogwisangu J, et al. A comparison of HIV stigma and discrimination in five international sites: The influence of care and treatment resources in high prevalence settings. Social Sci Med. 2009; 68(12): 2271-8. http://dx.doi.org/10.1016/j.socscimed. 2009.04.002

23. Bardin L. Análise de conteúdo. Lisboa: Edições 70; 2009.

24. Gibbs G. Análise de dados qualitativos. Porto Alegre: Artmed; 2009.

25. Cassady D, Jetter KM, Culp J. Is price a barrier to eating more fruits and vegetables for low-income families? J Am Diet Assoc. 2007; 107(11):1909-15. http://dx.doi.org/10.1016/j.jada.2007.08.015

26. Claro RM, Monteiro CA. Renda familiar, preço de alimentos e aquisição domiciliar de frutas e hortaliças no Brasil. Rev Saúde Pública. 2010; 44(6): 1014-20. http://dx.doi.org/10.1590/S0034-89102 010000600005

27. Brasil. Ministério da Saúde. A iniciativa de incentivo ao consumo de Frutas, Verduras e Legumes ( $F, L$ \& V): uma estratégia para abordagem intersetorial no contexto da Segurança Alimentar e Nutricional (CONSEA - Brasil). Brasília: Ministério da Saúde; 2005.

28. Walsh EM, Kiviniemi MT. Changing how I feel about the food: Experimentally manipulated affective associations with fruits change fruit choice behaviors. J Behav Med. 2014; 37(2):322-31. http:// dx.doi.org/10.1007/s10865-012-9490-5

29. Arnaiz MG. Em direção a uma nova ordem alimentar? In: Canesqui NA, Garcia RWD, organizadores. Antropologia e nutrição: um diálogo possível. Rio de Janeiro: Fiocruz; 2005. p.147-64.

30. Garcia RWD. Reflexos da globalização na cultura alimentar: considerações sobre as mudanças na alimentação urbana. Rev Nutr. 2003; 16(4):483-92. http://dx.doi.org/10.1590/S1415-52732003000 400011

31. Brasil. Ministério da Saúde. Secretaria de Atenção à Saúde. Guia alimentar para a população brasileira. Brasília: Ministério da Saúde; 2014.

Recebido: maio 12, 2015

Versão final: julho 16, 2015

Aprovado: setembro 8, 2015 
